DOI 10.37882/2223-2982.2020.04.14

\title{
ВЫЗЫВАНИЕ РЕЧИ У ДОШКОЛЬНИКОВ С РАССТРОЙСТВАМИ АУТИСТИЧЕСКОГО СПЕКТРА ПОСРЕДСТВОМ ПРИЕМОВ СЕНСОМОТОРНОГО РАЗВИТИЯ
}

\section{THE EVOCATION OF SPEECH IN \\ PRESCHOOL CHILDREN WITH \\ DISORDERS AUTISTIC SPECTRUM \\ THROUGH TECHNIQUES SENSORIMOTOR DEVELOPMENT \\ S. Leshchenko \\ N. Peshkova}

Summary: The article reveals the relevance of studying the speech development of preschool children with autism spectrum disorders and developing a program to induce speech in this category of children through sensorimotor development techniques. The features of the development of expressive speech in preschool children with autism spectrum disorders are considered. The program for speech evocation in this category of preschoolers by means of sensorimotor development techniques is described in detail, and the evaluation of the program's effectiveness is presented. This article will be of interest to specialists working with preschoolers with autism spectrum disorders.

Keywords: preschool children with autism spectrum disorders, expressive speech, sensorimotor development, correctional and developmental work.

\section{Введение}

$\mathrm{B}$ последнее время в мире возрастает число детей с различной патологией. Среди многочисленных форм нарушений развития проблема расстройства аутистического спектра (РАС) является одной из наиболее актуальных.

Расстройство аутистического спектра всегда является последствием неврологического нарушения центральной нервной системы ребенка. Как самостоятельное проявление, без неврологической причины, РАС существовать не может.

Одно из серьезных нарушений при РАС - это нарушение развития речи. Речь, как наиболее молодая функция центральной нервной системы, страдает в болезни в первую очередь и восстанавливается постепенно, поэтапно. Исходя из вышеописанных фактов, предлагаем направить все усилия на развитие и коррекцию гнозиса, праксиса детей с РАС, что повысит их эмоциональный тонус, и будет активизировать центральную нервную
Лещенко Светлана Геннадьевна

К.nсх.н., дочент, Тульский государственный педагогический университет им. Л.Н. Толстого

svet-lanal@mail.ru

Пешкова Наталья Александровна

К.псх.н., доцент, Тульский государственный педагогический университет им. Л.Н. Толстого na_peshkova@mail.ru

Аннотация: В статье раскрыта актуальность изучения развития речи дошкольников с расстройствами аутистического спектра и разработки программы по вызыванию речи у данной категории детей посредством приемов сенсомоторного развития. Рассмотрены особенности развития экспрессивной речи у дошкольников с расстройствами аутистического спектра. Подробно описана программа по вызыванию речи у данной категории дошкольников посредством приемов сенсомоторного развития, а также представлена оценка эффективности программы. Данная статья будет интересна специалистам, работающим с дошкольниками с расстройствами аутистического спектра.

Ключевые слова: дошкольники с расстройствами аутистического спектра, экспрессивная речь, сенсомоторное развитие, коррекционно-развивающая работа.

систему. А также рекомендуем стимулировать речевое развитие аутичных детей путем занятий по физическому, сенсорному и музыкальному воспитанию.

\section{Аитературный обзор}

Фундаментом умственного развития ребенка является сенсорное воспитание. Зрение, слух, обоняние и другие виды чувствительности входят в состав чувственного познания, разные уровни которого - ощущение, восприятие и представление - образуют его структуру.

Г. Фолькельт, Ф. Крюгер показали, что восприятие на ранних ступенях неотделимо от эмоциональной реакции. Ф. Крюгер предложил назвать восприятие «чувствоподобным» и отметил, что лишь с течением времени восприятие постепенно освобождается от связи с непосредственным аффектом, то есть с непосредственной эмоцией ребенка [2].

Многие исследования природы и структуры особенностей развития детей с РАС подтверждают гипотезу 
о гиперсензетивном восприятии, свойственном им на ранних этапах онтогенеза. При РАС большинство поступающих сенсорных сигналов воспринимаются как избыточные, ребенок вынужден обучаться процессам «игнорирования», снижения интенсивности поступающего сигнала. Формируется механизм защиты от «внешних воздействий». Вместо последовательного развития и совершенствования сенсорных систем в направлении изучения окружающего мира развивается механизм игнорирования внешних сигналов. Ребенок с РАС тренирует механизмы фиксации, добиваясь максимального самопоглощения свойствами выделяемого объекта. То есть дети воспринимают минимум сенсорной информации, избегаются яркие сенсорные стимулы, не формируется синтез различных сенсорных систем, бинакулярное зрение и бинауральный слух, но формируются аутостимуляции, «замещающие» и «подкрепляющие» стереотипии.

В зависимости от тяжести дефекта РАС во многом оказывает влияние на различные стороны развития детей: могут возникнуть трудности при формировании познавательных процессов, нарушается воображение, речевое развитие, отмечаются проблемы при мыслительных операциях, трудности в общении, может происходить нарушение социального и эмоционального взаимодействия в эмоционально-волевой и сенсорной сферах.

PAC накладывает на процесс познания окружающего мира определенный отпечаток, вносит специфику, проявляющуюся в динамике развития и накопления языковых средств, выразительных движений, своеобразии соотношения слова и образа, содержании лексики, некотором отставании формирования речевых навыков, не остаются в стороне и проблемы при формировании словаря, лексической, фонетической грамматической стороны речи, все это сказывается на общем развитии ребенка.

Проблемами РАС в нашей стране занимались В.М. Башина [1], К.С. Лебединская [3], М.М. Либлинг [4], С.С. Мнухин [6], О.С. Никольская [8] и другие. Самое раннее упоминание об аутизме (1943г.) принадлежало американскому клиническому психологу Л. Каннеру. Параллельно ему, педиатр из Австрии Г. Аспергер в 1944 году описал этот синдром. А в 1947 году русский исследователь С.С. Мнухин предоставил свою работу по данной проблеме [6].

В настоящее время наиболее известными и авторитетными работами по РАС являются труды К.С. Лебединской [3], О.С. Никольской [8], М.М. Либлинг [4]. О.С. Никольской принадлежит классификация детей с РАС, учитывающая степень проявлений аутизма [8].

Все ученые отмечают особый характер нарушений речи, и в первую очередь подчеркивается нарушение ее коммуникативной функции: имеющиеся речевые возможности не направлены на социальное взаимодействие, а при отсутствии речи ни жест, ни мимика не используются в целях компенсации.

Несмотря на увеличение в последнее время исследований, связанных с выявлением особенностей развития детей с РАС, проблема развития речи данной категории детей изучена недостаточно, несмотря на то, что сейчас наиболее часто встречаются именно неречевые дети с РАС. По данным зарубежных авторов (Л. Каннер, С. Эдельсон, Б. Римланд и др.), мутизм отмечается примерно у $50 \%$ детей с РАС, отечественные авторы чаще указывали частоту в 25-30\% (Т.И. Морозова, К.С. Лебединская, О.С. Никольская и др.), но в последние годы появилось все больше оснований согласиться с западными коллегами. Таким образом, в настоящее время остро существует потребность в разработке программы по вызыванию речи у дошкольников с РАС посредством приемов сенсомоторного развития.

\section{Методы исследования}

Для решения поставленных целей и задач в работе использовались следующие методы исследования:

- организационные: сравнительный, лонгитюдный;

- эмпирические: психолого-педагогический эксперимент в единстве трех этапов; психодиагностические (С.С. Морозова, С.В. Исханова, О.С. Никольская, Л.Г. Нуриева, М. Уокер) [7].

- анализ продуктов речевой деятельности;

- количественный и качественный анализ результатов исследования;

- интерпретационные методы.

Морозова С.С. предлагает диагностировать импрессивную и экспрессивную стороны речи, как в спонтанной ситуации, так и в направленном обследовании [7]. Для обследования импрессивной речи в спонтанной ситуации берутся параметры понимания высказываний, которые содержат аффективно значимые слова, выполнение инструкций в контексте ситуации и выполнение инструкций вне контекста. В направленном обследовании Морозова С.С. применяет параметры понимание названий предметов, понимание названий действий и понимание названий качеств предметов. При обследовании экспрессивной стороны речи в спонтанной ситуации берутся параметры вокализации внегортанные и звукообразные, подражание, выражение желаний, собственные высказывания. Экспрессивная речь оценивается по следующим параметрам: подражание, произносительная сторона речи, лексика, грамматическая структура речи. 
Исследование было осуществлено в два этапа:

Первый этап - наблюдение за детьми, организация и проведение констатирующего этапа эксперимента на основе выделенных параметров и критериев оценок.

Второй этап - исследование на основе взаимодействия с ребенком.

В исследовании приняли участие 10 дошкольников с расстройствами аутистического спектра.

\section{Ход эксперимента и его результаты}

Анализ продуктов речевой деятельности показал, что у дошкольников с РАС отмечается низкий уровень речевого развития. Понимание названий предметов если присутствует, то на бытовом уровне или в рамках своей темы. Отсутствует понимание действий и качеств предметов. Видно, что уровень развития пассивного словаря у детей с РАС выше, чем активного. Экспрессивная речь отсутствует у всех продиагностированных детей. У детей с РАС при ряде речевых нарушений отмечается общая моторная недостаточность, выраженная в разной степени, а также отклонения в развитии движений пальцев рук. Так как, формирование речевых областей совершается под влиянием кинестетических импульсов от пальцев рук и всего тела в целом, мы предусматриваем коррекционно-развивающие мероприятия в данном направлении.

Цель программы: стимуляция речевой активности детей с РАС посредством приемов сенсомоторного развития.

Задачи программы:

1. формирование и развитие речевой активности;

2. создание доверительных отношений детей со взрослыми (ведущим группы и помощниками), формирование и развитие взаимодействия детей с РАС с педагогами;

3. смягчение общего фона сенсорного и эмоционального дискомфорта, тревоги, страхов;

4. физическое развитие (расширение индивидуального двигательного опыта ребенка, воспитание физических качеств, развитие координации движений, равновесия, умения ориентироваться в пространстве, развитие мелкой моторики, укрепление здоровья ребенка, поддержание у него бодрого жизнерадостного настроения);

5. сенсорное воспитание (развитие и утончение зрения, слуха, осязания, обоняния, вкуса, барического чувства и стереогноза);

6. развитие интереса к изобразительной деятельности, музыке;

7. формирование целенаправленного поведения.
Форма организации образовательного процесса групповая и содержит три блока.

Первый блок занятия проходит в сенсорной комнате, где происходит прием детей в группу, реализуется свободная деятельность детей, приветствие на наборном полотне, отметка в календаре и игры в кругу. «Круг» включает в себя следующие игры и упражнения: приветствие (на данном этапе происходит формирование указательного жеста и других способов несловесной коммуникации. Для вызывания речи и стимуляции речевой активности мы используем стихотворения с вопросами и ответами, повторами и восклицаниями. Данные игры и стихи способствуют развитию умения сказать «я» и указать на себя); ритмические игры с эмоциональным заражением (эмоциональное заражение способствует вызыванию речи: учим детей понимать смысл самых простых слов и произносить их. При рассказывании стихов-потешек, взрослые сопровождают их простыми действиями (раскачивания, наклоны, хлопки) и вовлекают детей в эти движения); сенсорные игры (способствуют развитию коммуникативных возможностей, стимуляции речевой активности, развитию познавательного интереса и сенсорно-двигательной активности ребенка. Передавая по кругу звучащую или вибрирующую игрушку, шишку, раковину с «шумом моря», баночки с запахами, зеркальце и т.д., учим детей пониманию простых действий: «дай, возьми, на» [9]); игры на подражание (развитие речевого подражания, развитие мелкой и крупной моторики, научение детей повторять движения отраженно. Особое внимание уделяется побуждению ребенка к проявлению собственной активности, запоминанию сложных моторно-двигательных программ, специальным упражнениям (например, стимулирующим межполушарное взаимодействие). Дети с тяжелыми нарушениями развития учатся брать игрушку, совершать с ней простые игровые действия, ставить ее в определенное место. Одно и то же действие поочередно выполняется каждым ребенком, как, например, в играх «Ты, веревочка, крутись...», «Строим дом». В играх с предметами дети могут усвоить бытовые подробности, важные для развития представлений об окружающем их предметном мире (например, «Одеваем куклу»). Детям с выраженными нарушениями психо-эмоционального развития предлагают передавать друг другу интересную игрушку. В этом случае взаимодействие между участниками Круга становится более активным, дети положительно воспринимают друг друга); игры по правилам (развитие коммуникативных способностей, понимание и выполнение простых речевых инструкций. Один из детей исполняет роль водящего. Чаще всего эта роль сводится к совершению одного действия - кинуть мячик кому-нибудь, найти игрушку, спрятанную у другого, выбрать кого-то из детей и позвать его к себе. Становясь водящим в игре, ребенок оказывается в поле внимания других детей. Он должен проявить себя, совершить выбор. Таким образом, у ре- 
бенка развивается представление о собственном «я»); окончание Круга (формирование различных способов коммуникации и взаимодействия детей друг с другом. Дети и взрослые становятся в круг и, держась за руки, увеличивают его. После того как все максимально расходятся, «пузырь лопается» со звуком «Ш», и круг опять становится маленьким).

Ведущим специалистом этого блока является логопед, а дефектолог и психолог выступают в роли помощников.

Важным элементом среды является ее эмоциональное и сенсорное наполнение. Для занятия подбираются игры, которые содержат разнообразные сенсорные воздействия (в том числе тактильные). Эмоциональная насыщенность - необходимое условие проведения Круга. Взрослые «заражают» детей своими эмоциями, стремятся все время находиться в контакте с ними. Организовать внимание и активность детей в Кругу помогает ритм. Он побуждает ребенка к активности, деятельности. Аутичным детям, для которых ситуация общения является очень напряженной, ритм дает возможность сначала просто удержаться в ней, а потом и начать участвовать [5].

Целью второго блока занятия является коррекция психического развития ребенка с помощью методов сенсорной стимуляции (в работе используются настольно-печатные игры, работа с сенсорными альбомами, упражнения на развитие графомоторных навыков, продуктивна деятельность (рисование, аппликация, лепка). Занятия направлены на стимуляцию развития и утончения чувственного опыта детей, развитие мотивации к активной познавательной деятельности, снижение агрессии, тревожности. Развитие сенсорной чувствительности - необходимое условие для дальнейшей успешной работы по коррекции уровня психофизического развития ребенка. Все действия во время занятий сопровождаются четкими и понятными речевыми инструкциями.

Третий блок - музыкальное или физкультурное занятие.

Работа по физическому воспитанию проводится один раз в неделю в физкультурном зале, длительность занятия составляет 30 мин.

Основными задачами по моторно-двигательному развитию являются: развитие кинестетического восприятия, стимулирование двигательной активности, формирование представления о собственном теле, развитие ориентировки в пространстве и координации движений обеих рук, рук и ног, формирование умения выполнять движения по подражанию, по образцу, по команде, фор- мирование ритмичности движений и умения выполнять движения под музыку.

Работа по музыкальному воспитанию проводится один раз в неделю музыкальным руководителем по своей утвержденной программе, длительность занятия составляет 30 мин.

Занятия способствует коррекции эмоциональной и сенсорной сферы, внимания, речи, представлений об окружающей действительности, произвольности, серийности и выразительности движений и пр.

Также к основным задачам по музыкальному воспитанию относятся: релаксация психологического тонуса, переживание собственной успешности в музыкальной деятельности, развитие чувства ритма и музыкального восприятия (высота, сила, темп), развитие умения прислушиваться к звучанию музыкальных инструментов и самостоятельно действовать звучащими игрушками, инструментами, воспитание у детей интереса к музыкальным занятиям, желания участвовать в музыкальных играх, поддерживание активности детей, стимулирование увлеченности и заинтересованности на занятиях.

Каждый блок занимает по 30 минут. Продолжительность одного занятия - 1 час 30 минут; периодичность - два раза в неделю.

Все занятия необходимо проводить в присутствии родителей или помощников. Выступая в роли активных участников игр, взрослые поддерживают интерес к игре, помогают каждому ребенку чувствовать себя комфорTHO.

Для оценки результативности и эффективности составленной нами программы, направленной на вызывание речи у дошкольников с РАС было проведено повторное обследование речи у детей экспериментальной группы. При этом характер предлагаемых заданий остался неизменным.

Анализ результатов проведенной нами работы на контрольном этапе эксперимента показывает, что у детей с РАС при исследовании пассивного запаса речи улучшилось понимание высказываний, содержащих значимые слова, они стали лучше выполнять инструкции в рамках ситуации, больше понимать названия действий, но не качеств предметов. При исследовании активного запаса речи больше детей смогли ситуативно образовывать звуки и произносить слово. Следовательно, систематическая, последовательная и целенаправленная работа по вызыванию речи у детей с РАС посредством приемов сенсомоторного развития эффективна, но требует более длительного времени на реализацию. 


\section{Зак^ючение}

Представленные результаты свидетельствуют о необходимости проведения работы по вызыванию речи у детей дошкольного возраста с расстройствами аутистического спектра посредством приемов сенсомоторного развития. Благодаря эмоциональному заражению дети с
РАС начинают постепенно воспринимать сенсорную информацию, активизируя центральную нервную систему. Таким образом, путем занятий по физическому, сенсорному и музыкальному воспитанию идет и стимуляция речевого развития детей с РАС, так как речь является одной из функций центральной нервной системы.

1. Башина В.М. Аутизм в детстве. М.: Медицина, 1999.

2. Выготский Л.С. Лекции по психологии. СПб.: Союз, 1997. 144 с.

3. Лебединская К.С., Никольская О.С. Диагностика раннего детского аутизма. М.: Просвещение, 1991.

4. Либлинг М.М. Подготовка к обучению детей с ранним детским аутизмом Дефектология, 1998, № 1. С. 69

5. Мамайчук И.И. Психокоррекционные технологии для детей с проблемами в развитии. М.: Генезис, 2010. 400 c.

6. Мнухин С.С., Зеленецкая А.Е., Исаев Д.Н. 0 синдроме «раннего детского аутизма» или синдроме Каннера у детей // Ж-л невропатологии и психиатрии им. С.С. Корсакова. 1967. № 10 С. 1501-1506.

7. Морозова С.С. Аутизм: коррекционная работа при тяжелых и осложненных формах М.: Гуманитар, ВЛАДОС, 2007. 176 с.

8. Никольская О.С., Баенская Е.Р., Либлинг М.М. Аутичный ребенок. Пути помощи. М.: Теревинф, 2000.

9. Янушко Е.А. Игры с аутичным ребенком. Установление контакта, способы взаимодействия, развитие речи, психотерапия. М.: Теревинф, 2004.

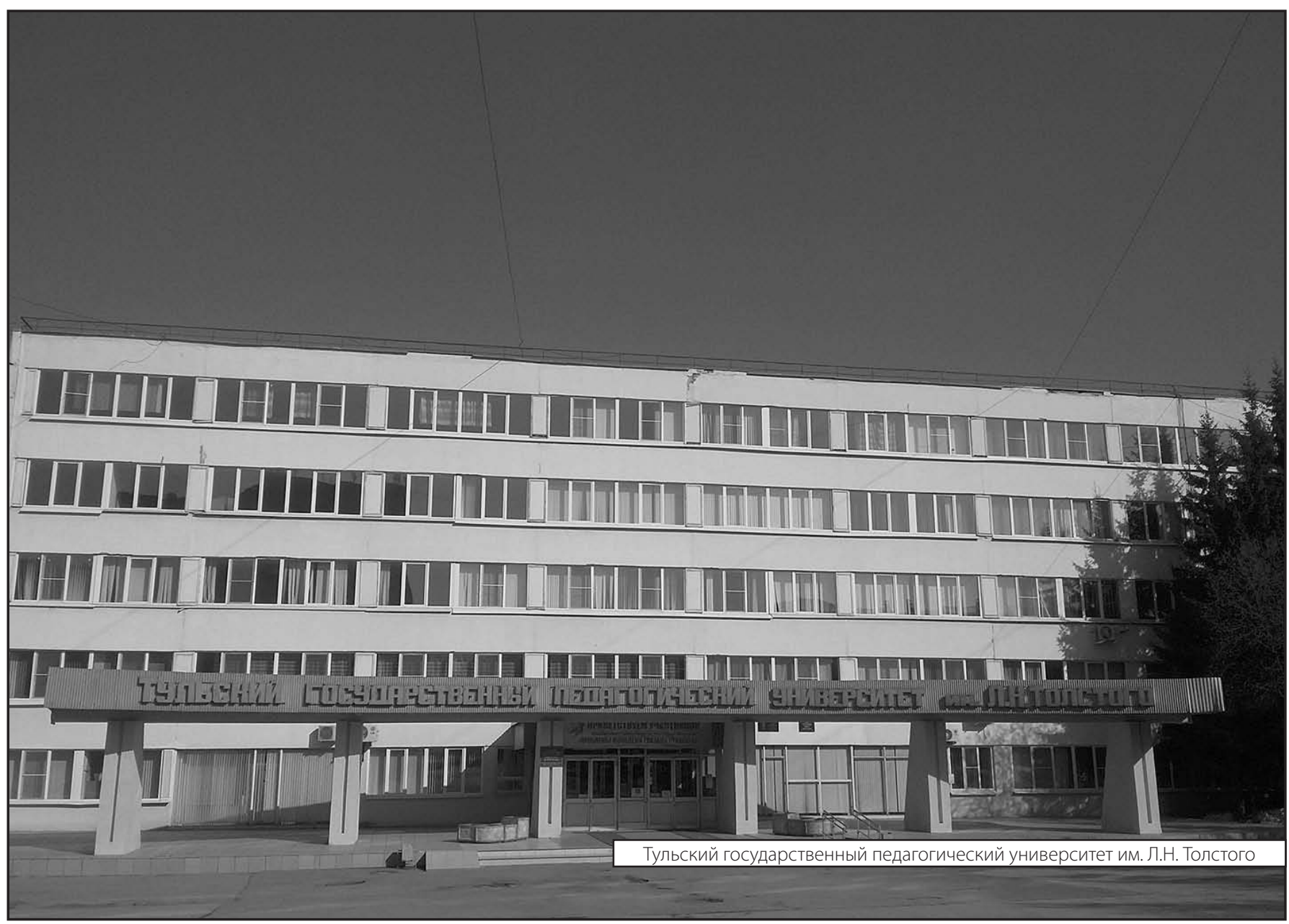

